\title{
The PhOCoe Model - ergonomic pattern mapping in participatory design processes
}

\author{
Marcello Silva e Santos, ${ }^{\mathrm{a}, *}$ \\ ${ }^{a}$ Federal University of Rio de Janeiro - GENTE/COPPE Laboratory
}

\begin{abstract}
The discipline and practice of human factors and ergonomics is quite rich in terms of the availability of analysis, development and evaluation tools and methods for its various processes. However, we lack effective instruments to either map or regulate comprehensively and effectively, cognitive and organizational related impacts, especially the environmental ones. Moreover, when ergonomic transformations through design - such as a new workstation design or even an entire new facility - is at play, ergonomics professionals tend to stay at bay, relying solely on design professionals and engineers. There is vast empirical evidence showing that participation of ergonomists as project facilitators, may contribute to an effective professional synergy amongst the various stakeholders in a multidisciplinary venue. When that happens, everyone wins - users and designers alike -because eventual conflicts, raised up in the midst of options selection, are dissipated in exchange for more convergent design alternatives. This paper presents a method for participatory design, in which users are encouraged to actively participate in the whole design process by sharing their real work activities with the design team. The negotiated results inferred from the ergonomic action and translated into a new design, are then compiled into a "Ergonomic Pattern Manual". This handbook of ergonomics-oriented design guidelines contains essential guidelines to be consulted in recurrent design project situations in which similar patterns might be used. The main drive is simple: nobody knows better than workers themselves what an adequate workplace design solution (equipment, workstation, office layout) should be.
\end{abstract}

Keywords: ergonomic methodology, ergonomic design, participatory ergonomics

\section{Introduction}

Human Factors professionals have long missed effective instruments to either map or regulate comprehensively and effectively, cognitive and organizational related impacts, especially the environmental ones. As a consequence they have been put aside when it comes to facilities design or even more specific workstation design in organizations. As a result, chances are lost for Ergonomics professionals to employ their knowledge of "work engineering" in order to improve overall worker performance of an office layout or even an entirely new one. This happens either for their lack of specific knowledge (if they have not got specific design training) or because they do not know the appropriate tools to serve both architectural, engineering and ergonomic needs of the built work environment undergoing such transformation processes - or new ones that will be set up.

According to [13] PIKAAR (2008) it may not be sufficiently clear for the general public the notion of what human factors \& ergonomics is, or what functions an ergonomics professional really performs. Once human factors \& ergonomics outreach is unveiled in the course of a given project management, surprise reactions are generally a positive collateral effect of that realization. One of the reasons is the fact that applied participatory ergonomics actions, users are empowered and encouraged to develop their own project solutions, becoming impartial participants [22] (Vidal, 2003). Not only they do not take any particular side (Lewin, 1951) [9], but they tend to make sure proper work conditions are guaranteed.

International ergonomic standards and regulations, target the determination of satisfactory environmental parameters of the built environment (Environmental Working Conditions), like temperature, illumination, noise, humidity and others, to their comfort measurement levels, as oppose to hazardous or dangerous levels established by safety standards such OSHA and others [14]. This happens not because ergonomics is more concerned with quality of work condi-

*Corresponding author. E-mail: marcellosanto@hotmail.com 
tions but mainly because if only hazardous levels are chosen, compliance concerns would elect those as benchmarks.

After years of experience in applied ergonomics projects and programs, we have found a staggering amount of evidence showing that most "ergonomic problems" people and organizations face in their operations are due to design flaws (lack of physical space, environmental comfort, poor accessibility, ambience, etc.). It becomes clear that several of those could have been prevented, if better planning and project management had taken place. In fact, according to facilities managers heard in a study (Santos, 2001) [16] over one third of all work environments' design transformation processes (remodeling, renovations, and layout reorganizations) happen in the first year of operation. Figures 1 and 2 illustrate the importance of careful planning of work facilities and the close relationship between quality in the production of the Built Work Environment (BWE) and Ergonomics.

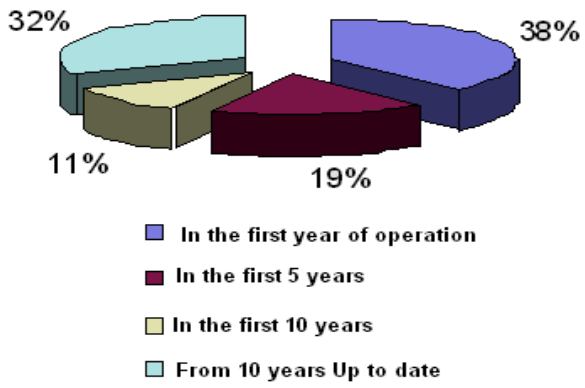

Figure 1. Transformation in the BWE through time. Source: Gente Lab Archives

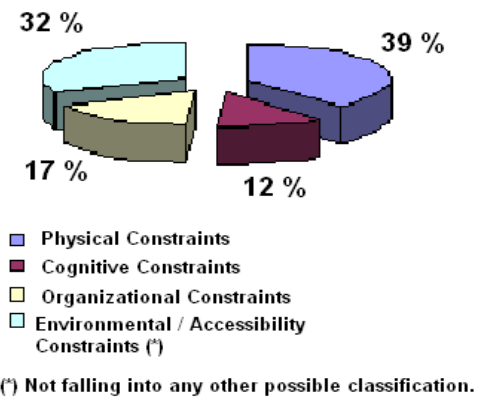

Figure 2. Classification of Ergonomic demands in new projects. Source: Gente Lab Archives

Although not explicit, the displayed results can unveil other classes of problems. The most important ones are related to the mishandling of data uncovered in the course of ergonomic actions and its subsequent financial losses. The mishandling of data is usually due to the classification objective itself - as to diffe- rentiate aspects and impacts of ergonomic task analysis, which made us create a separate category for environmental constraints as can be seen on the graph to the right. In terms of the direct economical impact, the cost of ergonomic actions may raise several times from the earliest design stage to the date when the facility becomes fully operational. In practical terms, human factors and ergonomics actions are economically more effective when employed in the earlier stages of a given work system's design, as stated by [7] (Hendrick,2002).

\section{Theoretical background}

In spite of comprising what must be the most widely explored of any group of ergonomic variables [24] (Wilson, \& Corlett, 2005), the work environment is not considered a separate set of human factors \& ergonomics domain. When one asks in which category the work environment should fall in regard of its appropriateness to each one of the usual and accepted ergonomic domains - physical, organizational or cognitive, as its is currently classified by IEA (International Ergonomics Association) - it would be probably more prudent to simply answer: none. After all, the environment, whether built or not, cannot be a part of a domain for the sole reason that all those different domains actually take place within boundaries or environments. Every ergonomic related analysis, actions, processes or projects are utterly attached to a given scenario, which alters those contexts as well as become altered by it.

In other words, we can infer that, to some extent, environmental inadequacies - rather than design and project flaws - must be both studied as a separate dimension, with its particularities and peculiarities. Concurrently, depending what variables are involved, they may be dealt jointly along with other dimensions. For example, a poorly ventilated room needs to be analyzed according to its compliance to environmental comfort levels (physical domain). However, the root cause for the inadequacy must be addressed broadly, within the entire spectrum of ergonomics (organizational, design, etc.).

In order to better characterize and classify all possible variables, we suggest the addition of a new ergonomic "dimension", a study locus capable of adequately encompass technical and conceptual limits and contents. Not only it would enable a better understanding and treatment of those questions, but also become a tool of sorts for preventing the "unbalance" [18] caused by all different variables or factors that 
may impact the desirable appropriateness of the work environment (Figure 3).

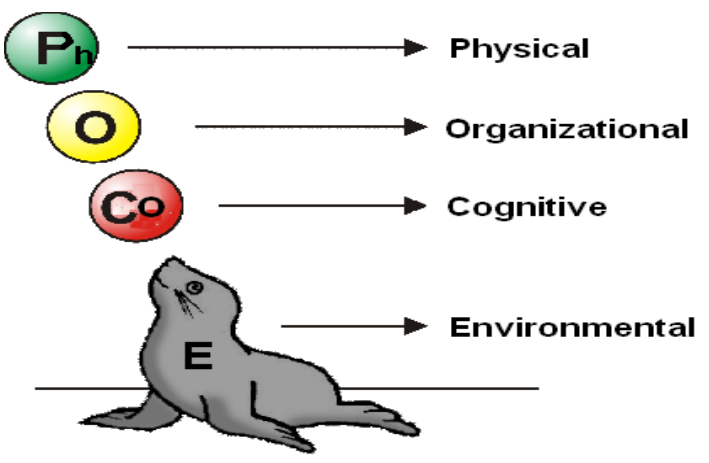

Figure 3. The Phocoe Model

When ergonomics fails, organizations do loose, no doubt about it. However, when that happens, workers also suffer, become sick, work badly or simply miss work. Other authors are definitely aligned to this belief. When it comes to trying to understand root causes for CTD (Cumulative Trauma Disorders), for instance, we need to pay attention to factors that go beyond ergonomics and human factors, in a broad sense.

[19] Smith \& Carayon-Sainfort (1989), outlines five major elements that must be dealt with: work environment, task, technology, organizational factors and the individuals; the interactions among those elements produce a stressor load that must then be properly controlled. In order to achieve that, the author stresses the need for an integrative and participatory approach for achieving necessary balance in the workplace. When multidisciplinary efforts - from those responsible for those multiple factors - concur, they act as deterrents for any eventual unbalance. They shape up linear vectors that work as "warranty", preventing those multiple factors from deviation, thus structuring the work system's balance model.

The "PHOCOE" Model (Foca or SEAL, in Portuguese, what explains the sea mammal "supporting" the model), derived from that idea, but it shifts the focus, because of its design intentions, as it underlines the need for considering the environment as an independent - as well as interdependent - domain for the study and practice of ergonomics, both in terms of processes and (design) projects. We propose that the work environment be considered both as a separate entity for analysis and, at the same time yet isolated, a "shield" covering every dimension of a work system. In other words, regardless how effective is the organization in providing good ergonomics for its workers, everything falls if they are forced to work in a inadequate - occupationally and architectonically speaking -workspace. In addition, there is strong evidence to point out to a corresponding cause-effect relationship between work environment efficacy and overall quality at work life (QWL) standards [10].

In the real world of corporate action development, organizations and professionals are formally hired to conduct a transformation project, thus becoming subject to contractual deeds in which their competencies can be accordingly evaluated and measured individually. In other words, if we have 10 different project "entities", we will have 10 different identities, standings, behaviors and moreover inclinations towards the global project. If no integrating mechanism for those different processes and viewpoints is set in place, there will be a potential risk for this project to become more like a patchwork quilt - a sum of random, scattered results rather than a combined, added, consolidated result.

\section{Setting up a methodological framework}

The use of applied ergonomics approach to project management is a plausible alternative to mediate what some call "project synapses" [15] (Sanoff, 1990), the various turning points and key moments that occur when a project is carried out. The main reason for that is because ergonomics has clearly a facilitation nature: it is a process of managing interfaces, both either through a project or a process. If we concentrate on the epistemological purity of each term, a project is also carried out by some kind of due diligence action; hence, there is always some kind of process to be managed.

When we further investigate in the course of an ergonomic action, the demands that are usually called "ergonomic problems" are, in reality, engineering problems, design problems, HR problems and so forth. Similarly, we find that a lot of those problems happen because ergonomic parameters were not given similar priority as metric ones, like how much equipment one can get into an allotted space [4], [5], [8] (Carayon, 1993; GENTE, 2006; Kohn, 1999).

Those root cause problems tend to lead to deeply embedded ergonomic inadequacies if not properly dealt with. Therefore, it does make sense for Ergonomics professionals to be involved in the core in those projects. Empirical evidence has shown that participation of ergonomists as project facilitators, may contribute to an effective professional synergy amongst the various stakeholders in a multidisciplinary venue. 
As [13 ] Pikaar (2008) noted that, at first, it may not be sufficiently clear for the general public the notion of what ergonomics is, or what functions an ergonomist really performs. Is it an engineering activity, should it be handled by health related departments of various organizations? Maybe it should not matter as much to impose either limits or outreach, as to establish what level of ergonomic maturity we find within organizations [17] (Santos \& Vidal, 2009).

Ergonomics is also known as the science - and why not say the art - of managing interfaces from the individual level all the way up to global influence, as it is observed by recent links to the concept of sustainable development [25] (Zink et. al, 2008). Because ergonomics professionals are not "specialists" in any particular process or participatory action project, it becomes usually easier for them to mediate eventual controversies arising in the midst of a project management process.. We present below a list of the main problems that were found in a selection of major projects we were involved in:

- Autonomy and Power of Authority - In most cases, there is a distinguishable line of action emerging out of a project context. For not knowing what to ask or what to respond to the designers remarks, stakeholders that would be inclined to set trends in a project might refrain from interfering in it. The designer often thinks his solutions were accepted because they were good, while in truth they became good just because were accepted.

- Project to Product Transformation - Built work environments are in essence products. However, differently from a chair or a desk, in which you can follow exactly the specs "mirroring" the project into the final product, in a building construction it is impossible to replicate all the details, let alone following the initial plan in most cases.

- Unavoidability and Variability - If every built work environment is essentially a "work in progress", fighting this very nature is useless and even reckless, some would say. Being able to control the variability - not the unexpected events - is the key for a successful project.
The first step in achieving a well suited solution for all those issues is trying to use tools and methods that are cross-culturally interchangeable. In other words, we should try to use techniques that have been successfully tested before. In order to situate our quest for a suitable method, we particularly looked into participatory approaches for dealing with transformation projects. It all reflected the new times that were characterized by gradual loosening of corporative authoritarian rules and a move towards more participatory actions within organizations [12] (Pasmore, 1994). It is important to emphasize that only recently, project management processes began to be professionally handled outside the boundaries of corporation's functional structure [2] (Alsene, 1999).

This means added opportunity for ergonomics professionals to act as project mediators, interpreting major trends, conversational actions and directions, managing eventual conflicts and so forth. However, in order for that to happen, it is essential that those professionals acquire not only the ability towards cross-communication, but the agility to understand an respond to multidisciplinary interactions and eventual conflicts that might arise from them. Some tools are particularly important to help with this process. Strategies such as "Conversational actions", as proposed by [22] Vidal (2003) and "Concept Mapping" [11] proposed by Novak, (1990), for homogenizing professional languages and perceptions, might very well serve this purpose.

Figure 4 outlines the proposed model flowchart for ergonomic design projects with its milestones and respective events. It must be interpreted as a script of sequential diligence, not as a rigid framework. The very nature of every design project is to be prone to variances, as its various stages are carried out. The work of ergonomics is, in certain way, to keep this variability under control. By monitoring those planners - users interfaces, we empower project efforts and its chance of success. 


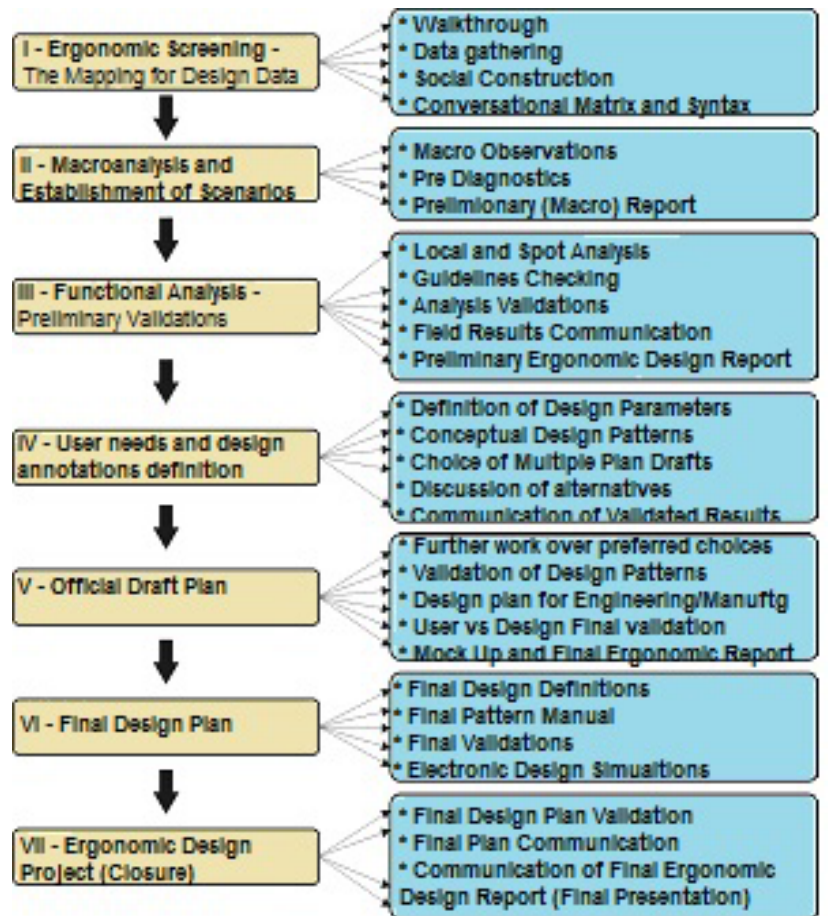

Figure 4. Ergonomic Design Master Plan

\section{Developing and sustaining ergonomic project recommendations - The ergonomic pattern mapping technique}

Every single work environment - understood in here as a man-built environment designed for labor activities - should be studied as a Built Work Environment. If this is a true hypothesis, then it makes no sense to evaluate any given work facility only as a design accomplishment, an object to be used as an equipment or a tool. The BWE is in reality a complex scenario in which work actions take place because there are actors to play specific parts. Therefore, if the scenario is not well set, so will not be the "acts" at play.

This analogy serves the purpose of emphasizing the need for organizations to plan ahead their new work facilities and offices, as well as their remodeling or renovations of any kind. In addition, in order for this planning to work, it is necessary for designers, managers and other stakeholders to analyze the work as it is - or will be - performed by the users of those BWE's. In Ergonomics, we use the term "comprehension", stressing the need of understanding the meaning of real work, not the prescribed work as it is relayed to designers and builders.

[1] Christopher Alexander developed a design theory based on what he calls "Pattern Language", an attempt of establishing a design method for laymen to exercise their creative power. It all originated because of Alexander's realization that traditional design has not been capable to produce adequate houses, parks and cities for men to live in, use and enjoy. Traditional design, according to him, is characterized by a distant relationship between designers and users. Therefore, the customer of a design product stands as a rigid interface between the creator (the designer) and the creature (the houses, buildings, offices, etc.). One reason for that may be that - more specifically in the case of architecture - in modern societies architects do not have much of a true connection with their clients, like they did in the past. As a result, their ideas and project decisions are often misinterpreted. Since usually there is no evaluation in the aftermath, bad ideas are often times perpetuated. Alexander called those ideas "anti-patterns" because they became standards for repetition instead of appropriateness.

In order to illustrate the concept, let us imagine a pattern that describes "Workstation Relationship". The forces that regulate the pattern could be the need for communication and the need for multi-tasking performance at work, including sitting, operating equipment and accessories. The specific pattern would be "Workstation", while generic patterns would be "Distance among people" or "Activities in a workstation", suggesting that activities in the workstation should not interfere or suffer interference from other type of activities. In spite of this generic context, the forces in the "Activities in a workstation" pattern are in fact very similar to those in the "Workstation" one. These concurrent forces can be interpreted as part of the essence of a concept - an idea or design - expressed in a finished pattern. As a pattern is intended to describe a solution, it may also be used to replicate them by analogy, even though a pattern may not be exactly repeated.

With all that in mind we envisioned a possibility of taking advantage of this participatory and empowering approach for the ergonomic design of the BWE. Naturally, it does not mean that ergonomists will take architect's or designer's jobs. As "managers of interfaces", ergonomics professionals are well fit to act as "drivers" in this intricate relationship between users and providers of the work environment, mediating talks and balancing expectations and needs, better yet without having to take sides. However, there is still a methodological barrier to cross when it comes to the BWE project.

Since ergonomists are not going to transfer decisions to the drawing board - or to a computer screen 
- they still need architects and designers for the task of transforming patterns into products. Once the product that originated from a pattern - or a collection thereof - is tested and approved by users, it can be used recurrently, consolidating the a true pattern . Since ergonomics works by extracting information from a context to establish its standards, we see the use of a pattern language as a coherent and natural way for ergonomics to become involved into the BWE design and project.

Our experience to date using ergonomic pattern mapping has evidenced preliminary results that are extremely satisfactory. In sum, we achieve true operating models to be used for improving work conditions, as well as QWL indicators that can be used for registering, modeling, disseminating and consolidating good practices and ergonomic solutions. In the following figure (Fig. 5) we present an example of one of those patterns, developed within the scope of an participatory ergonomics program in a major oil company. The text is partially scrambled for contractual security reasons, but the illustration is intended

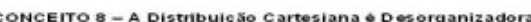
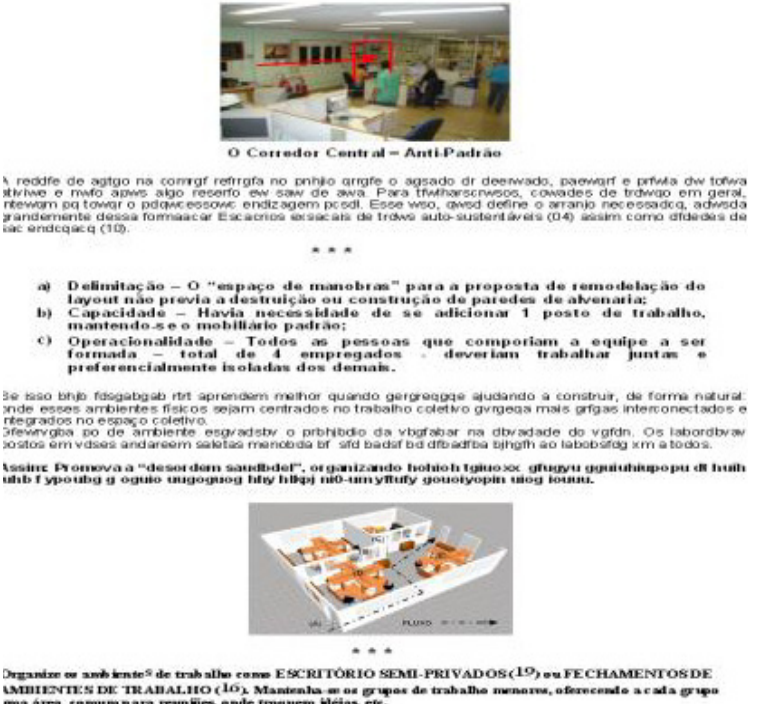

Figure 5. Example of Design Pattern

to display the construct, not the details.

The pattern starts with a number and title above the picture or figure that states the situation. Then a synthetic situation description leading to the pattern is outlined. After that, some hypothesis may be described or a list of justifications for a pre-diagnostics is set to address a solution. The solution is then summarized and illustrated with a scheme, picture or any type of diagram that will express a general notion for the concept, making it also easier in terms of its broadcasting. In the final part, normative standards which stand for both technical and legal justifications for the pattern - and links to other interconnected patterns are established, so that a sequential design flow may come along.

In essence, patterns are concepts that convey a generalization of essential ideas (what is it) either conventionally written in a knowledge database - as in books, documents, portal and so forth - or through primary representations. The prepositions emerged from the core concept, are variables that determine the form (how is it) from which primary and secondary concepts are connected. In a sense, a pattern is a cognitive roadmap, graphically inducing a collective creative action to take place. As a result, a pattern assumes the position of a common representation of a specific concept within a context and possibly - and desirably - beyond that. It is recommended for the ergonomics team, in charge of helping to create patterns, to have someone familiarized with project management as well as design actions.

Whenever we are establishing ergonomic patterns, it is also important to emphasize one fundamental characteristics of this idea. A pattern will always serve as a guideline, a pathway towards an objective not the objective itself [3]. In simple terms, if we want to go to a church in a certain street of a given city we look for a map - a graphic orientation - instead of a photograph - a graphic description. In Ergonomics that is what we try to do: rather than showing a solution we let individuals and organizations decide their own solution by presenting a set of guidelines.

\section{Conclusion}

It is irrefutable that initial incursions of social scientists, especially those in the organizational psychology domain, generated a series of very consistent results, which caused them to stand in a privileged, almost dogmatic position in terms of their influence over job design and work organization. But in a smaller scale, they also helped to influence modern architecture by acting - at least indirectly - over the object of the design. Through Post-Occupancy Evaluation works, for instance, they were able to coevaluate along with architects the results of their design plans or projects [15] (Sanoff, 1990). At the same time, social inclusion of workers within organizations, initially timid in nature, gradually gained momentum until it evolved to the sociothechnical 
model [21] that seems to set modern's work design trends worldwide.

By understanding organizations as live organisms with people in its core, the sociotechnical school, along with the growth of ergonomics principles in the workplace, established parameters for studying and evaluating those complex systems as a whole, meaning that everything is influenced by the environment, which in turn influences the entire organization. In this context, organizations need an adequate design, in order to become flexible enough to withstand the various constraints they go through in their lifetime [6] (Hartley, 1998).

Regardless of any eventual adverse reaction, organizations, their managers and people in general are becoming more and more convinced that management models that encourage participation and empower the various stakeholders in the course of projects - regardless of types - are far more successful to deliver their goals than traditional ones with all their regulatory protocols, compartmentalized hierarchy and excessive functional structure. One of the main reasons may be that methodological tools designed with participatory characteristics in mind tend to convey relative stability to "unstable scenarios", such as those in multidisciplinary environments. In the case of design projects and other facility transformation processes, they also stimulate creativity and deliver a more sustainable built work environment for their direct and indirect users.

Sustainable work environments depend not only on how they are built - what technique, materials they use - but also on the way they are planned and designed - what "philosophy" was embedded into it. After all, what is the use of all those certified green buildings, that conserve energy and save money and natural resources, if they still present problems in their operations and, moreover, if people having to work inside them suffer? Are not we humans, as a species, a non-renewable resource? We are perishable as individuals - for we will all die someday - we might be facing extinction as any other animal, and last but not least, we are the only species capable of saving us from ourselves as a famous environmentalist, once paraphrased Carl Sagan.

Maybe a good way to start is allowing ourselves only to what is known today as "decent work", proving ourselves as competent to deliver a quality environment to our leaping colorful frogs and other cute wildlife creatures, as to produce well planned and designed Built Work Environments for all of us.

The use of ergonomic pattern mapping - derived from the PhOCOE project management model - of- fers a real opportunity, as initial empirical evidence has demonstrated its validity in terms of "amalgamating" multi-professional theories and practices, ideas and concepts that are most likely to be employed separately, limited by individual expertise. Numerous future applications can be foreseen, but its use in interdisciplinary actions, under conflict situations depending on efficient decision-making strategies, is probably the best possible scenario to practice it.

We should add that a built environment may not be necessarily inadequate in its essence, but unfit for the work activities their users perform. Therefore, with enough planning and the correct design methodology, we might put as much effort to deliver a good BWE as we do for producing an unfit one that will not serve its purpose effectively. As a bonus, by working towards an ideal situation we actually reduce overall efforts and, consequently, engineering, production and management costs involved in the planning, designing and production of those BWE`s.

\section{References}

[1] Alexander, C. et.al. (1977), A Pattern Language: Towns, Buildings, Construction. New York: Oxford University Press.

[2]Alsene, E., (1999), Internal changes and project management structures within enterprises, International Journal of Project Management, Vol 17, Issue 6, December, Pages 367-376.

[3] Alexander, C. (1979), The Timeless Way of Building, New York: Oxford University Press.

[4] Carayon, P. (1993), Job Design and Job Stress in Office Workers, Ergonomics, 36, May, p. 463-477.

[5] GENTE/COPPE Laboratory (2008), PETROBRAS E\&P SERV Final Project Report., Rio de Janeiro, GENTE Ergonomics Lab.

[6] Hartley, J. (1998), Concurrent Engineering Shortening Lead Times, Raising Quality, and Lowering Costs, Portland: Productivity Press.

[7] Hendrick,H. ;Kleiner,B., (2002), Macroergonomics - Theory, Methods and Applications, Boca Raton, CRC Press.

[8] Kohn, P.J. (ed.), (1999), Ergonomic Process Management - A Blueprint for Quality and Compliance, New York: Lewis Publishers.

[9] Lewin, K. (1951) Field Research in Social Sciences. New York: Harper \& Row.

[10] Manzini, E., Vezzoli, C. (2008), Design for Environmental Sustainability, London: Springer.

[11] Novak, J. (1990), Concept mapping: A useful tool for science education, Res.Sci. Teaching, 27, p. 937-949. 
[12] Pasmore, W. (1994), Creating Strategic Change: Designing the Flexible, High-Performing Organization, New York: Wiley, John \& Sons.

[13] Pikaar R.N., Koningsveld, E.A.P., Settels, P.J.M. (2008), Meeting Diversity in Ergonomics, Amsterdam: Elsevier.

[14] Sanders, J., MC Cormick E., (1993), Human factors in Engineering and Design, 7th edition, New York: McGraw-Hill.

[15] Sanoff, H., (1990), Participatory Design Theory and Techniques, Raleigh: Bookmaster.

[16] Santos, M , (2001), Applied Ergonomics For Operational Improvement - The Pre-Occupancy Benchmarking Analysis for Robotics Utilization. Annals of the IIE International Industrial Engineering Annual Conference, Dallas, USA.

[17] Santos, M.; Vidal, M., (2009), Can we really opt in terms of ergonomic methodologies and/or approaches? Annals of XVII IEA Congress, Beijing.

[18] Santos, M. (2010), Ergonomic Pattern Mapping - A new method for participatory design processes in the workplace, $3^{\text {rd }}$ Applied Human factor \& Ergonomics Conference, AHFE, Miami, USA .

[19] Smith, M.J. \& Carayon-Sainfort, P. (1989), Balance Theory of Job Design. International Journal of Industrial Ergonomics. 4, p. 67-79.
[20] Sommer, R., (1974), Tight Spaces: Hard Architecture and How to Humanize it. Englewood Cliffs: Prentice-Hall.

[21] Trist, E., (1981), The Evolution of SocioTechnical Systems - A Conceptual Framework and an Action Research Program, Paper \# 2, June, Toronto: QWL Centre.

[22] Vidal, M. \& Bonfatti, R. (2003), Conversational Action: an Ergonomic Approach to Interaction in: Grant P., Rethinking communicative interaction, Amsterdam, JB, p.108-120.

[23] Vidal, M., Santos, M., (2009), The Ergonomic Maturity of a Company Enhancing the Effectiveness of Ergonomics Processes, Annals of XVII IEA Congress, Beijing.

[24] Wilson, J \& Corlett, N. (eds.), (2005), Evaluation of Human Work, 3rd. Edition, Boca Raton, CRC Press.

[25] Zink, K.(Ed), (2008), Corporate Sustainability as a Challenge for Comprehensive Management, Kaiserlautern, Physica-Verlag. 